\title{
Analysis on the Influencing Factors of Farmers' Income in Heilongjiang
}

\author{
Dehua Zhang* \\ Harbin University of commerce, \\ Harbin Heilongjiang 150028, China \\ zdh19841027@163.com
}

\begin{abstract}
The farmers in Heilongjiang have made a significant contribution to national food security, but they always have been plagued by the lower income. Based on the macro data of farmers' income, this paper selects the multiple linear regression models and uses stepwise to analyze the influencing factors of farmers' income in Heilongjiang. The results show that per capita crop sown acreage, the average amount of chemical fertilizer, national investment in agriculture, secondary or higher education accounted for an average of one hundred labor are the main influencing factors of farmers' income in Heilongjiang. Ultimately, the paper puts forward suggestions: promoting the large-scale planting, improving farmers' own quality and introducing the talents of indigenous knowledge, striving for national preferential agricultural policies and transferring surplus labor by cross-border in Heilongjiang.
\end{abstract}

Keywords-Heilongjiang; farmers; influencing factors of income; multiple linear regression model; preferential agricultural policies; transfer the labor.

\section{INTRODUCTION}

Heilongjiang is our nation's largest commodity grain base. Grain output reaches 55.705 billion $\mathrm{kg}$ in 2011, of which commodity grain output is up to 45 billion $\mathrm{kg}$ and becomes the first major grain-producing province; meanwhile, Heilongjiang also ranks first in total output, commodity grain output and food self-sufficiency rate in the whole nation [1]. 15 billion $\mathrm{kg}$ commodity grain is contributed by Heilongjiang Reclamation among 45 billion $\mathrm{kg}$. Its commodity grain rate is more than $90 \%$ and farmers in Heilongjiang have made great contributions to guarantee national food security [2]. However, there is still a large gap for farmers' income comparing with developed areas, such as Shanghai and Beijing. How to guarantee farmers' income growth in Heilongjiang becomes a major problem in its future development. Therefore, the paper analyzes the related influencing factors of farmers' income in Heilongjiang which is particularly important.

Through combing the previous studies, the paper selects 14 variables and analyzes the relevant research data using multiple linear regression models and strives to achieve the authenticity and accuracy of the study.

\section{MODEL CONSTRUCTION}

\section{A. Multiple linear regression models}

The purpose of this study is to analyze the influencing factors of farmers' income and identify the main reason influencing farmers' income. So for the model application, the paper selects multiple linear regression models to analyze the selected data and the specific form of the model is following: (1).

$$
Y=C+\sum_{i=1}^{n} \beta_{i} X_{i}+\varepsilon
$$

$Y$ represents farmers' income, $C$ is a constant, $\beta_{i}$ is the regression coefficients of corresponding variable, $X i$ is the corresponding variable, $\varepsilon$ is a random disturbance term and $n$ ranges from 1 to 21 .

1) Variable Selection and theoretical assumptions

Farmers' income in Heilongjiang is influenced by many factors, through reading and organizing the relevant literature, the paper comes to the specific factors affecting farmers' income, mainly including: operating scale factors, human factors, the national investment factors, tax factors, technological factors, infrastructure factors, structural factors, market factors, urbanization factors and labor transfer factors $[3,4]$. So this part selects 14 indicators as the main indicators to influence farmers' income in Heilongjiang: $X_{1}$ (per capita sown area of farm crops), $X_{2}$ (the proportion of average hundred labors from junior secondary or higher school), $\mathrm{X}_{3}$ (the number of rural labor), $\mathrm{X}_{4}$ (national investment in agriculture), $\mathrm{X}_{5}$ (average consumption of Chemical fertilizers), $\mathrm{X}_{6}$ (average total agricultural machinery power), $\mathrm{X}_{7}$ (irrigated area), $X_{8}$ (the proportion of grain sown area), $X_{9}$ (the proportion of income from household operations), $X_{10}$ (the proportion of agricultural output), $\mathrm{X}_{11}$ (price indices fro means of agricultural production), $\mathrm{X}_{12}$ (producer price indices for farm products), $\mathrm{X}_{13}$ ( the proportion of urban population) and $\mathrm{X}_{14}$ (the proportion of rural labor engaging in primary industry).

2) Data selection

According to the selected influencing factors indicators and "Heilongjiang Statistical Yearbook", "China Statistical Yearbook" and "China Rural Statistical Yearbook," the paper sorts out the relevant data from 1990 to 2010 and analyzes them.

\section{ANALYSIS ON MODEL ESTIMATION RESULTS}

Using SPSS software, the paper analyzes the above data with multivariate linear regression. The Stepwise method screens for influencing factors gradually, reserves the most representative factors and analyzes the specific impact on farmers' income. The paper comes to the final conclusion by SPSS software (shown in Table 1 and Table 
2).

From the above analysis results, we can see that the paper keeps 4 variable indicators among 14 indicators, including per capita sown area of farm crops $\left(\mathrm{X}_{1}\right)$, average consumption of Chemical fertilizers $\left(\mathrm{X}_{5}\right)$, national investment in agriculture $\left(\mathrm{X}_{4}\right)$ and the proportion of average hundred labors from junior secondary or higher school $\left(\mathrm{X}_{2}\right)$. Among the former three models, the irrigated area is the first indicator to be retained, which shows that it has the most obvious influence on farmers' income in Heilongjiang and it has the strongest representation on farmers' income. But in the fourth model the effective irrigated area is out, the reason is that national investment in agriculture and effective irrigated area has a significant correlation. The paper introduces national investment in agriculture which is a strong alternative for effective irrigated area and the correlation between the two indicators also affects the results of the model variables $t$ test. Per capita sown area of farm crops is the second indicator entering the model, indicating that its significance is less than effective irrigated area. Because of joining the per capita sown area of farm crops, determination coefficient of the model amounts to 0.966, which has a rise of 0.034 . Average consumption of Chemical fertilizers is the third indicator entering the model, determination coefficient of the model amounts to 0.985 , which has a rise of 0.019 . National investment in agriculture is the fourth entering the model and its determination coefficient has a rise of 0.05 . After removing the effective irrigated area, the proportion of average hundred labors from junior secondary or higher school enters the model for the last indicator and its determination coefficient is 0.991 (shown in Table 1-2).

By linear regression analysis results, we can see that after six screening, $\mathrm{R} 2$ of the model 6 is $0.991, \mathrm{R}^{2}$ is 0.989 after the adjustment, which is much greater than 0.8 , indicating the good fitting effect of the model. $\mathrm{F}=$ 431.442 , and $\mathrm{sig}=0.000<0.05$, which indicates that the model has passed the F-test and rejects the null hypothesis; indicating that the explained variables and the explaining variables has the obvious linear relationship (shown in Table 3-4). The main factors influencing farmers' income in Heilongjiang are $X_{1}$ (per capita sown area of farm crops), $\mathrm{X}_{5}$ (average consumption of Chemical fertilizers), $\mathrm{X}_{4}$ (national investment in agriculture) and $\mathrm{X}_{2}$ (the proportion of average hundred labors from junior secondary or higher school). They all pass the $t$ Test under the significant level of $5 \%$ and the Sig. is $0.000,0.001$, 0.000 and 0.003 respectively which is less than 0.05 . The coefficient is 2627.22, 19.717, 0.267 and 22.076 . Eventually, decisive equation of farmers' income in Heilongjiang is $\mathrm{Y}=-4191.323+2627.22 \mathrm{X}_{1}+19.717 \mathrm{X}_{5}$ $+0.267 \mathrm{X}_{4}+22.076 \mathrm{X}_{2}+\varepsilon$. We can see from the equation, when per capita sown area of farm crops in Heilongjiang increases a unit, namely 1 hectare, farmers' per capita net income will increase 2627.22 yuan. When average consumption of Chemical fertilizers increases a unit, namely $1 \mathrm{~kg}$, farmers' per capita net income will increase 19.717 yuan. When national investment in agriculture increases 1 unit, namely 0.1 billion yuan, farmers' per capita net income will increase 0.267 yuan. When the proportion of average hundred labors from junior secondary or higher school increases 1 unit, namely one percent, farmers' per capita net income will increase 22.076 yuan.

\section{DISCUSSION ON MODEL ESTIMATION RESULTS}

By multiple linear regression analysis, the main factors influencing farmers' per capita net income in Heilongjiang are $X_{1}$ (per capita sown area of farm crops), $\mathrm{X}_{5}$ (average consumption of Chemical fertilizers), $\mathrm{X}_{4}$ (national investment in agriculture) and $\mathrm{X}_{2}$ (the proportion of average hundred labors from junior secondary or higher school). The paper will discuss the model estimation results and analyze the influential path and conductive effect of each influencing factor.

(1) Per capita sown area of farm crops is the scale factor. From the above analysis, we come to the conclusion that per capita sown area of farm crops has the positive correlation with farmers' per capita net income. Comparing with other factors, it has the greatest impact on farmers' income. When it increases a unit, farmers' income increases 2627.72 yuan, indicating that farmers' income growth in Heilongjiang has a high correlation with per capita sown area of farm crops in the multiple linear regression model. The actual situation also confirms this point, per capita sown area of farm crops in Heilongjiang has been in a rising trend in recent years. Entering the 2003, with the implementation of stimulated policies on food production, per capita arable land in Heilongjiang is still rising steadily. Per capita sown area of farm crops increases through expanding the scale, then the output increases which brings income growth. Abundant arable land resources in Heilongjiang provide a strong impetus for farmers' income growth. Because of the scarcity and limitation of land scale, the income growth pattern which obtains profit by expanding the scale can't be the long-term income growth pattern [5].

(2) The average consumption of Chemical fertilizers is the technology factor. The consumption of Chemical fertilizer is one of the technological factors. Among the multiple linear regression models, if it increases a unit, farmers' net income will increase 19.717 yuan in Heilongjiang. The average consumption of Chemical fertilizers transfers to each crop production through the materialized, then to the total crop production and finally to the income through production. The actual situation exactly confirms this point that soil fertility and the "continuous cropping" phenomenon is more prominent through the research in Heilongjiang. On the one hand, there is a significant decrease in the black soil, the farmers themselves can feel that the soil color isn't blacker than before and the natural fertility of the land also decreases rapidly. On the other hand, grain sown area accounts for about $95 \%$ of the sown area of farm crops which the distinctive grain production characteristics. In recent years, in order to increase the income, farmers choose paddy fields instead of dry fields in general. Some dry fields 
can't be changed which plant corns and only in the lower temperature region can plant soybeans which result in the common "continuous cropping" phenomenon and some areas don't change the crops in more than consecutive five years. Considering the above two factors, farmers' planting is gradually expanding in the dependence of fertilizer. The factor influencing farmers' income is long-standing; the average consumption of Chemical fertilizers will increase in the future and the application methods of fertilizer will be constantly updated. This shows that under the situation of scarce land resources and outflow human resources, the technological factors have a great positive role in promoting farmers' income growth [6].

(3) National investment in agriculture is input factor. National investment in agriculture is one of the input factors. Among the models, if it increases 0.1 billion yuan, farmers' income will increase 0.267 yuan. The state increases fiscal spending on agriculture, rural areas and farmers. On the one hand, it can be materialized on the rural infrastructure and public utilities, it promotes agriculture productivity and people's living standards in terms of agricultural production and life, thereby it increases farmers' income and decreases farmers' income spending. On the other hand, farmers obtain funds in the form of direct subsidies which directly contributes to the growth of farmers' income. Since 2007, the state implements four subsidies on grain, agricultural resources, improved seeds and agricultural machinery, rapidly increases agricultural spending limits which directly promotes farmers' income growth. This suggests that input factor plays a two-way role in farmers' income growth, which can be materialized to the infrastructure and the means of production related with agricultural production and can also act directly on the income growth [7]. In farmers' income growth process in the future in Heilongjiang, the input factor is bound to become one of the key growth momentums. To achieve modernized agriculture in Heilongjiang remains strong national and local financial support. Therefore, farmers' foreseeable income growth in the future will depend on the investment growth in a long term in Heilongjiang.

(4) The proportion of junior secondary or higher school is the quality factor. It is the concrete manifestation of the cultural quality of the labor force. This part is the macro-longitudinal analysis, so the cultural quality of the labor force is also the proportion of average hundred labors from junior secondary or higher school in macro aspects. In the multiple regression models, if it increases 1 unit, farmers' income will increase 22.026 yuan. Cultural quality of the labor force has an indirect role in increasing farmers' income. When farmers' cultural quality is improved, their decision-making, market judgment, technology-using and the ability to master knowledge will be greatly improved, and thus they achieve the effect of income growth. Technological factors are closely related with farmers' cultural quality, when farmers' quality is improved, their ability to learn and master advanced technology will be greatly improved. For example, farmers can freely master the amount of chemical fertilizer and its usage. The reality is just like this, through the research we find that the higher the farmers' educational level is, the stronger their ability to master new technologies is, and they also have some insights on the market's judgment. Farmers' income growth in Heilongjiang in the future needs the continuous improvement of farmers' quality. Cultural quality of the labor force will be a long-term influencing factor and its importance will continue to increase.

\section{DISCUSSION}

The paper studies the influencing factors on farmers' income in Heilongjiang which has a strong practical guiding significance. It has some practical significance to ensure national food security, increase farmers' income and maintain social stability. Based on the analysis of a single factor from previous studies, the paper attempts to study more factors comprehensively and finds the main influencing factors by using multiple linear regression method which has some innovations in research perspective [8]. Its drawback is that the factors influencing farmers' income is very complex, the paper can only choose some relatively important factors to analyze; therefore it still has a certain sidedness. Through the research, we find that $X_{1}$ (per capita sown area of farm crops), $\mathrm{X}_{5}$ (average consumption of Chemical fertilizers), $\mathrm{X}_{4}$ (national investment in agriculture) and $\mathrm{X}_{2}$ (the proportion of average hundred labors from junior secondary or higher school) has a significant impact on farmers' income in Heilongjiang which is consistent with previous studies. However, because Heilongjiang has distinctive characteristics of major grain-producing areas, the source of farmers' income mainly depends on food production, thus the conclusion of the study is also influenced which shows certain particularity [9]. We can see that per capita sown area of farm crops becomes the most representative influencing factor on farmers' income in Heilongjiang, while the labor-transferring factor doesn't become the major influencing factor. The main reason is that Heilongjiang has always considered food production as the main economy source and food economy in rural areas is in a dominated position. Under the premise of a considerable level of technology, the greater farmers' food production and operation scale is, the higher their income is relatively [10].

\section{ACKNOWLEDGMENT}

The paper is funded by the following items. $\mathrm{PhD}$ Research Project Started of Harbin University of Commerce (14RW10); Science and Technology Project of Heilongjiang Provincial Education Department (12541191).

\section{CORRESPONDING AUTHOR}

Dehua Zhang,

email:zdh19841027@163.com, mobile phone: $15846097095 ; 18545107516$ 


\section{REFERENCES}

[1] Du Yuhong and Huang . Fiscal Xiaozhou. Study on the relationship between fiscal funds agricultural expenditure and Farmers' Income [J]. Statistical Research, 2006 (9): 47-49

[2] Shi Xianhua and Chen Ming. Survey and recommendations on the current causes of farmers' income slowing growth--taking Chuzhou in Anhui Province as an example [J]. Scientific Socialism, 2007 (4): 33-35

[3] Song Lili, Guo Jingli and Wang Xiudong. Dynamic branching study on Chinese farmers' income since the reform and opening up [J].Issues of Agricultural Economy, 2010 (Suppl) :189-195

[4] Ke Bingsheng. Reflections on the problems of farmers' income in China [J]. Issues of Agricultural Economy, 2005 (1): 25-32

[5] $\mathrm{Xu}$ Hui and Li Dongsheng. Typically related analysis from educational human capital influencing on farmers' income [J]. Agricultural technology economy, 2011 (8) :44-49
[6] Tang Min and Wu Benyin. Farmers' income growth model: a macro-econometric analysis [J]. Issues of Agricultural Economy, 2007 (8): 81-85

[7] Zhang Wenli and Liu Haibing. Establishing long-term mechanism on farmers' income growth with fiscal support [J]. Agricultural technology economy, 2008 (2): 80-84

[8] Zeng Jianzhong. The reasons and countermeasures on farmers' income growth are difficult in Hainan [J]. Issues of Agricultural Economy, 2009 (1): 99-102

[9] Yang Huan and Li Feng. The analysis of relationship between per capita schooling years of rural laborers and farmers' income [J]. Chinese Vocational and Technical Education, 2011 (12): 50-52

[10] Li Dasheng and Li Qin. Influencing mechanism and empirical research from agricultural technological advances on farmers' income [J]. Agricultural Technology Economy, 2007 (3): 23-27

TABLE 1. VARIABLE SELECTION

\begin{tabular}{ccc}
\hline Model & Variables Entered & Variables Removed \\
\hline 1 & irrigated area & \\
2 & per capita sown area of farm crops & \\
3 & average consumption of Chemical fertilizers & \\
4 & National investment in agriculture & Irrigated area \\
5 & & \\
6 & the proportion of average hundred labors from junior secondary or higher school & \\
\hline
\end{tabular}

TABle 2. MODEl ABSTRACT

\begin{tabular}{ccccc}
\hline Model & R & R Square & Adjusted R Square & Std. Error of the Estimate \\
\hline 1 & $0.965(\mathrm{a})$ & 0.932 & 0.928 & 396.21016 \\
2 & $0.983(\mathrm{~b})$ & 0.966 & 0.962 & 289.19592 \\
3 & $0.993(\mathrm{c})$ & 0.985 & 0.983 & 193.89051 \\
4 & $0.995(\mathrm{~d})$ & 0.990 & 0.987 & 168.80642 \\
5 & $0.994(\mathrm{e})$ & 0.988 & 0.986 & 176.09602 \\
6 & $0.995(\mathrm{f})$ & 0.991 & 0.989 & 158.66901 \\
\hline
\end{tabular}

TABLE 3. VARIANCE ANALYSIS

\begin{tabular}{ccccccc}
\hline Model & & Sum of Squares & df & Mean Square & F & Sig. \\
\hline 6 & Regression & 43447666.149 & 4 & 10861916.537 & 431.442 & $.000(\mathrm{f})$ \\
& Residual & 402813.660 & 16 & 25175.854 & & \\
& Total & 43850479.810 & 20 & & & \\
\hline
\end{tabular}

TABLE 4. REGRESSION COEFFICIENTS

\begin{tabular}{|c|c|c|c|c|c|c|}
\hline \multirow{2}{*}{ Model } & & \multicolumn{2}{|c|}{ Unstandardized Coefficients } & \multirow{2}{*}{$\begin{array}{c}\text { Standardized Coefficients } \\
\text { Beta }\end{array}$} & \multirow{2}{*}{$\mathrm{t}$} & \multirow{2}{*}{ Sig. } \\
\hline & & B & Std. Error & & & \\
\hline \multirow[t]{5}{*}{6} & (Constant) & -4191.323 & 756.377 & & -5.541 & .000 \\
\hline & $\mathrm{X}_{1}$ & 2627.22 & 1031.82 & .292 & 2.546 & .022 \\
\hline & $\mathrm{X}_{5}$ & 19.717 & 4.311 & .222 & 4.574 & .000 \\
\hline & $\mathrm{X}_{4}$ & .267 & .070 & .429 & 3.805 & .002 \\
\hline & $\mathrm{X}_{2}$ & 22.076 & 9.933 & .132 & 2.222 & .041 \\
\hline
\end{tabular}

